ISSN 00156043

\title{
ESTUDIOS
}

\section{La formación moral en las asignaturas universitarias de ciencias humanas y sociales}

\author{
Raúl González Fabre, SJ'
}

Palabras clave: Universidades jesuitas, formación moral, ciencias humanas y sociales.

Key words: Jesuit Universities, moral education, humanities and social sciences.

\section{Introducción ${ }^{2}$}

La educación jesuita ha considerado siempre la formación personal de sus estudiantes como el centro de su misión. Cuando se trata de la universidad, lo que podría parecer una tautología (¿en qué otra cosa consiste educar sino en formar?) no necesariamente lo es. Dos tipos de fuerzas tienden a distraernos de la formación de los estudiantes como personas. Ambas se expresan en las muy efectivas presio-

\footnotetext{
' Cátedra Javier Benjumea -ICADE- UP Comillas. Versión final del 15 de mayo 2008.

2 Una versión preliminar de este papel fue presentada en una sesión pública sostenida en ESADE (Barcelona) el 1 febrero de 2008. Se trata de una ponencia pedida al autor por el Grupo de Éticas Profesionales de UNIJES (asociación de las universidades y centros de educación superior de los jesuitas en España). Este grupo de trabajo reúne a profesores de asignaturas de ética profesional, con la finalidad de discutir sobre estrategias e instrumentos para mejorar la formación que se ofrece en los centros asociados a UNIJES. Una de las cuestiones recurrentes del grupo es cómo convertir toda la experiencia universitaria de nuestros estudiantes en lugar de formación moral de futuros profesionales. En ese contexto, se nos solicitó la ponencia que ahora publicamos. En el diálogo que siguió a su lectura, nos beneficiamos de los comentarios y sugerencias de profesores de diversas universidades jesuitas españolas y del IESE (Universidad de Navarra). Aunque no podemos citarles de manera precisa a partir de nuestras notas, el autor les expresa su más sentido agradecimiento. Las deficiencias remanentes son, sin embargo, nuestras por entero.
} 
nes ejercidas sobre la universidad tanto por el mercado como por las autoridades públicas atentas a él.

Por una parte, se requiere de la universidad que produzca graduados ampliamente dotados de conocimientos y habilidades, lo que últimamente se resume bajo el expresivo término de "competencias" 3 . Se nos piden graduados competentes para hacer competitivas a nuestras empresas y nuestras economías en el fluido contexto económico global. Sólo si ofrecemos eso, haremos competitivas a nuestras universidades en la captación de estudiantes. Los jóvenes apreciarán el reconocimiento del mercado a nuestros títulos y los prospectos de carrera derivados de ese reconocimiento, comenzando por la vital 'empleabilidad'.

Por otra parte, se demanda de la universidad que contribuya con investigación pura y aplicada a la innovación y el desarrollo, claves para el éxito empresarial y el crecimiento económico desde hace un par de siglos. La universidad debe entonces colocar papers en journals prestigiosos, registrar patentes de utilidad industrial, desarrollar proyectos conjuntos con el sector privado y el público, publicar ideas seminales que luego sean ampliamente citadas. Si lo hace mejor que otras, verá subir su posición en los diversos rankings de instituciones académicas, lo que a su vez le será de gran utilidad para su marketing entre estudiantes, empresas y donantes varios.

Todas estas demandas son, sin duda, pertinentes y legítimas. Ninguna universidad jesuita podría desentenderse de ellas sin arriesgar su viabilidad y, al mismo tiempo, traicionar su misión en cuanto ésta incluye contribuir efectivamente a la creación social, tal como ella ocurre en nuestros días. Sin embargo, dado que las demandas de 'competencias' e 'innovación' se nos dirigen en un contexto crecientemente competitivo en todos los mercados, incluido el de la enseñanza universitaria, existe un cierto riesgo de que el esfuerzo por estar a la altura respecto a ellas nos distraiga de un aspecto menos demandado, que las empresas quizás aprecian pero no pagan, y los rankings académicos apenas consideran, porque es difícil de cuantificar: la formación de los estudiantes en cuanto personas, en particular su formación moral para el ejercicio profesional ${ }^{4}$.

${ }^{3}$ La elección de "competencias" es tanto más expresiva cuanto que "capacidades" en el sentido de Sen y Nussbaum estaba también disponible.

${ }^{4}$ Esto viene a ser una especificación de las tensiones recogidas en las tesis 7 y 8 de ROMERO (2007). 
Para cubrir este aspecto decisivo de su misión, las universidades jesuitas ${ }^{5}$ suelen contar con una asignatura de ética profesional en los últimos cursos de todas sus carreras, a veces acompañada de otras asignaturas de antropología filosófica, religiosa, social, o relacionadas, en los primeros cursos. Esas asignaturas contribuyen sin duda a otorgar a la universidad jesuita un perfil propio, con una oferta que incluye elementos de "una educación que armonice la riqueza del desarrollo humanístico y cultural con la formación profesional especializada"6.

Se trata, sin embargo, sólo de algunos elementos. Si tuviéramos un diseño curricular de cuatro años con tres asignaturas semestrales de este tipo, la reflexión antropológica, social y moral tendría reservado sólo el $5 \%$ del esfuerzo académico de los estudiantes. Como no puede ser de otra manera, el grueso de nuestros currículos se dedica a los fundamentos teóricos, primero, y a los desarrollos prácticos, después, de la formación profesional especializada que define a las correspondientes carreras.

Por ello, la formación moral de nuestros estudiantes ocurrirá, en un sentido o en otro, muy principalmente en las asignaturas básicas y aplicadas propias de cada carrera. De ellas, argumentaremos, las más decisivas son las que contienen o utilizan visiones teóricas de la persona y de la sociedad. Este artículo va así dirigido en primer lugar a profesores universitarios que deben formar a adultos jóvenes en disciplinas científicas humanas y sociales. Constituye un recuento sobre las variadas maneras en que el trabajo de esos profesores se relaciona con la ética.

Comenzamos mostrando a grandes rasgos en qué consiste la dimensión moral de la existencia humana [epígrafe 2] y cuáles son los temas centrales de la ética como disciplina [3]. Seguimos indicando algunos elementos centrales de la formación moral [4] y de cómo acontece ésta en la universidad jesuita [5]. La especificidad de las asignaturas de ciencias humanas y sociales respecto a la formación moral en la universidad es tratada bajo dos aspectos: los contenidos teóricos de las asignaturas [6.1], y los 'otros contenidos' con que el profesor pone en relación la teoría con el mundo profesional concreto para el que prepara a los estudiantes [6.2]. En un breve excurso examinamos la aplicabilidad de las discusiones anteriores a las ciencias formales y naturales [7]. Terminamos notando el rol del gobierno universitario en la articulación de algunos componentes fundamentales para el buen éxito de la formación moral en nuestras universidades [8].

\footnotetext{
${ }^{5}$ Lo que decimos de las universidades jesuitas puede extenderse, mutatis mutandis, a muchas otras universidades católicas y de inspiración cristiana; también a universidades de inspiración humanista.

${ }^{6}$ Ex Corde Ecclesiae (1990), 23.
} 


\section{La dimensión moral de la existencia humana}

En este artículo utilizaremos las palabras ética y moral como sinónimos etimológicos, para referirnos a una misma experiencia humana fundamental: la de elegir de manera intencional y libre entre una pluralidad de opciones que se nos presentan en las encrucijadas pequeñas y grandes de la vida. Elegimos después de haber valorado cada una de las alternativas descubiertas por nuestra inteligencia, y lo hacemos conscientemente, combinando racionalidad con sensibilidad, procesos interiores con influencias exteriores. De esa primera experiencia de elegir, brota una segunda igualmente fundamental: a través de nuestras elecciones intencionales y libres, nos vamos configurando a nosotros mismos en unas ciertas formas de ser, influimos sobre las formas de ser de otras personas, y redibujamos junto con ellas rasgos del mundo que compartimos y co-creamos.

En la posibilidad de elegir se juega, de hecho, la conformación de aquello de nosotros mismos y de nuestro mundo sobre lo cual tenemos un mayor control, lo que no nos viene impuesto sino que depende de nuestras opciones, la parte de la realidad que nos permanece abierta, donde somos propiamente personas y no meras piezas complejas de un mecanismo complejo. Tiene entonces sentido que podamos ser llamados a responder por nuestras elecciones y sus efectos queridos o permitidos sobre nosotros mismos y sobre los demás. La responsabilidad acompaña sin cesura al ejercicio de la libertad moral.

Por otra parte, si la persona actúa de manera intencional y libre, sus decisiones no pueden ser predichas con la misma relativa facilidad con que se predice el movimiento de una cosa o incluso la conducta de un animal. Esquemas explicativopredictivos como 'causa-efecto' o 'estímulo-respuesta' no bastan para dar cuenta de situaciones en que el sujeto puede elegir el efecto que tendrá la causa que le presiona, o la respuesta que dará a un estímulo que le afecta.

Nuestra experiencia moral primera constituye además la clave hermenéutica de nuestro modo cotidiano de apreciar los comportamientos de los demás. Para explicarnos o para predecir el comportamiento personal de otro no nos basta con saber a qué influencias o condicionamientos externos está sometido, sino que es preciso además aventurar un juicio sobre qué calidades de ser personal posee y quiere poseer, qué calidades relacionales persigue en sus interacciones, a qué aspectos de la construcción social del mundo desea contribuir y de cuáles se ha desentendido. Sólo si acertamos en este juicio, nos acercaremos a saber qué puede esperarse de él, en qué términos puede obtenerse su colaboración, qué confianza puede depositarse en su persona. Como se notará, éste es un asunto de la mayor importancia práctica en cualquier contexto profesional. 


\section{El discurso que se ocupa de la dimensión moral}

El discurso académico que se ocupa de la dimensión moral de la vida humana suele llamarse ética. A los efectos de esta exposición, consideraremos en él cuatro grandes áreas temáticas.

La primera podría denominarse antropología moral, que forma parte de la antropología filosófica. Estudia en qué consiste la posibilidad de elegir, explorando los hechos básicos del comportamiento humano inteligente y libre, su carácter real o ilusorio, primordial o derivado, la articulación de lo individual y lo social en él, su conexión con otros aspectos de la realidad humana, etc. La antropología moral hace esto con una intención principalmente descriptiva.

Supuesto que la posibilidad de elegir efectivamente existe, y no constituye una mera ilusión mental, la segunda gran área temática de que se ocupa la ética es cómo elegir acertadamente. La discusión correspondiente se desenvuelve en varios niveles. El más fundamental estudia en qué consiste en general una elección moral acertada, qué principios la rigen y cómo engranan con la estructura moral del ser persona que la antropología describe. A partir de ahí pueden proponerse metodologías de decisión moral, y desarrollar casuísticas que ilustren la aplicación de esos métodos a ámbitos particulares de decisión. Aunque se utilizan saberes descriptivos, el objetivo último de esta segunda área de la ética es, sin embargo, normativo.

Por otra parte, puesto que las elecciones morales resultan en conductas observables, pueden estudiarse también, desde un punto de vista tanto descriptivo como valorativo, las configuraciones del mundo de las personas a que dan lugar. Se trata del estudio de las formas de socialización e influencia moral, de las costumbres, de los procesos por los que llegan a ser y se modifican, etc. Así, la tercera gran área de la que se ocupa la ética incluye la dimensión moral de la antropología cultural, que es descriptiva y empírica, y la crítica social, más valorativa y normativa.

Finalmente, en el terreno de los instrumentos, una cuarta área de la ética se ocupa del lenguaje y la lógica con que se habla de todo lo anterior, con especial atención a los procesos de derivación de conclusiones normativas. 


\section{La formación moral}

El punto de partida del humanismo cristiano, y de hecho de todos los humanismos, es que la experiencia inmediata del ejercicio de la libertad de elegir corresponde a la esencia humana, y es por tanto real, no ilusoria. Ello implica rechazar la idea de la persona humana como un mecanismo completamente determinado, sea por sus bases físicoquímicas, sea por estructuras externas a él, por ejemplo sociales. Ese punto de partida puede argumentarse sin gran dificultad a la manera de Descartes, puesto que si pudiéramos dudar de una experiencia tan inmediata a nuestra conciencia como la de poder elegir efectivamente, con más razón deberíamos dudar de las percepciones sensoriales necesarias para construir ciencias sobre las que apoyar una visión mecanicista o estructuralista del ser humano.

Como señalamos arriba, la actividad moral de las personas es la región más propiamente personal de sus vidas, aquella en que gobiernan sus actos, los cuales pasan a ser en verdad propios suyos. De ahí que deban responder por ellos. Por otra parte, la acción moral no sólo es apropiada personalmente por el sujeto que la elige, sino que se apropia de él, confiriéndole calidades morales que adquiere a través de sus elecciones intencionales y libres. Finalmente, la acción moral viene a ser el ámbito de su existencia donde el sujeto mejor puede elegir el sentido en que su actividad contribuirá a la vida de los otros y a la construcción del mundo de todos.

La importancia del ejercicio moral de las personas es pues muy grande, tanto por lo que está en juego como por tratarse del espacio donde el sujeto no está prisionero de pre-determinaciones internas o externas, y puede por tanto hacer que su acción sea una $u$ otra, apuntada intencionalmente a unos $u$ otros resultados para sí mismo y para los demás. Se entiende entonces que la formación moral constituya en todas las culturas humanas un elemento central de la educación de los jóvenes. La educación física, la emocional y la intelectual son importantes, pero lo que la persona finalmente haga con ellas dependerá en buena medida de las calidades morales que haya podido adquirir, y de las opciones morales con que quiera seguir gobernando su vida.

Salvo quizás en los primeros estadios del crecimiento de la persona, cuando las bases psicosomáticas de la libertad aún no se han desarrollado lo suficiente, la educación moral no puede consistir en un condicionamiento para ajustar las conductas a lo que el educador tenga por deseable. Educar no es programar a través de la repetición de esquemas cerrados estímulo-respuesta, sino al contrario, ofrecer elementos para que la persona elija por sí misma en situaciones abiertas, donde le cabe descubrir posibilidades varias y discernir cuál será mejor. 
En la educación moral deben articularse tres elementos: uno intelectual, otro afectivo, y un tercero volitivo. La educación de la inteligencia moral capacita para descubrir la existencia e importancia de la dimensión ética en la actividad propia y ajena, en las relaciones interpersonales y en las impersonales o estructurales. Capacita también para reconocer las cuestiones morales cuando se presentan, para identificar las posibilidades alternativas que se abren a nuestra decisión, y para valorarlas de manera razonable, prudente y coherente, usando métodos que permitan elucidar racionalmente los desacuerdos y alcanzar unidad de acción con otros.

La educación de la afectividad moral procura ajustar los sentimientos y otras emociones al mejor bien que la inteligencia es capaz de descubrir en las posibilidades que se nos abren en cada situación. En ese sentido, cultiva intuiciones y sensibilidades básicas que a menudo entran en juego antes de razonar sobre la situación, orientando en cierta manera al razonamiento mismo. Gracias a la afectividad moral, somos capaces de desear lo mejor y gustarlo cuando lo vemos realizado.

Finalmente, la formación de la voluntad capacita para elegir, querer y realizar el bien que la inteligencia nos señala como mejor en la situación, superando la adhesión interna a bienes menores, asumiendo los sacrificios personales y los costes sociales que sean precisos.

La educación moral no es programación del educando, sino más bien una propuesta cuya efectividad depende de su acogida por quien la recibe. La experiencia de siglos de educación moral en Occidente muestra la importancia de que los aspectos intelectuales, los afectivos y los volitivos se encuentren bien engranados en el sujeto. Los desajustes son posibles. El camino de muchos infiernos terrestres está empedrado de buenas intenciones no acompañadas de una comprensión inteligente de la situación y sus posibilidades. Y es recorrido por muchos sujetos que, al menos en un momento dado, supieron perfectamente lo que era mejor hacer, pero no se atrevieron a ello. Al final, como las disonancias sólo pueden mantenerse un cierto tiempo, existe el riesgo de que inteligencia moral, afectividad y volición se ajusten mutuamente a la baja, de manera que el sujeto se vuelva a la vez ciego a la dimensión moral de su actividad, insensible a lo que está en juego en ella, e impotente para actuar contracorriente de pulsiones internas y presiones externas fuera de su control. Una persona así, armada con un título universitario y puesta en una posición profesional de cierto poder e influencia, resulta, ni que decir tiene, extremadamente peligrosa. Ejemplos sobran. 


\section{La formación moral en la universidad jesuita}

En los ciclos primero y segundo de la universidad debe ocurrir la última transición entre la adolescencia y la adultez. Se trata de una etapa de gran importancia en la conformación moral del sujeto, quien a menudo entra en ella en una posición social poco diferente a la de un niño, y sale habilitado para desempeñar responsabilidades adultas en el mundo profesional. La universidad jesuita se toma muy en serio este tránsito: tiene entre sus objetivos centrales proponer a los estudiantes una formación ética capaz de orientarles e inspirarles en su vida profesional futura. En este epígrafe presentaremos algunas de las formas en que la universidad jesuita contribuye a ese proceso de maduración moral del estudiante, dejando para el próximo apartado lo que corresponde específicamente a las asignaturas de ciencias humanas y sociales.

Parte esencial de la formación universitaria consiste en tratar al estudiante como adulto, sin paternalismos, para que en el ejercicio se acostumbre a serlo si no lo era ya. Todos tenemos experiencia de las dificultades del tránsito, y de cómo en él se juega en muchos casos el éxito o fracaso académico del estudiante. Incorporarse como adulto a una estructura burocrática con reglas iguales para todos que se administran con justicia y prudencia, contribuye sin duda a la maduración moral del estudiante, aunque eventualmente genere conflictos con quienes son menos capaces de comprender esa lógica. Por el contrario, el profesor que pliega las reglas a las expresiones emocionales de algunos de sus alumnos, condescendiendo paternalistamente a las inmadureces de los más adolescentes, tal vez obtenga mejores resultados en las encuestas, pero estará dejando una parte importante de su trabajo educativo sin hacer. Lo mismo puede decirse, obviamente, del empleado administrativo, del directivo, o de las instancias colegiadas de gobierno, todos los cuales, en una universidad, son inevitablemente educadores.

La universidad jesuita cuenta normalmente con algunas instancias extraacadémicas de formación moral, tales como servicios de pastoral, compromiso social y cultura. Dependiendo del diseño de sus programas, se ocupan más o menos de la formación intelectual para el ejercicio moral, pero en ellas se cuida siempre la formación de los afectos y la volición, despertando sensibilidades y ofreciendo oportunidades de actuar en función de ellas, adquiriendo valiosas experiencias personales sobre las que luego se reflexiona. Esta oferta de exploración vivencial por el estudiante mismo no debe ser en manera alguna menospreciada por la estructura propiamente académica. De hecho, en ella se abren posibilidades de formación moral que difícilmente pueden desarrollarse desde el aula. Sin embargo, por la misma naturaleza de estos servicios, la participación en ellos suele ser 
voluntaria y por lo general involucra sólo a una minoría, parte de la cual ya estaba previamente motivada.

Además, según mencionamos arriba, prácticamente cada carrera de nuestras universidades cuenta en sus últimos cursos con una asignatura de ética, que incluye temas tanto de ética general como de ética específica para la profesión en cuestión. Para apoyar a estas asignaturas, el Grupo de Éticas Profesionales de UNIJES viene publicando una colección de manuales que proponen una discusión ética adecuada a cada profesión, desde un enfoque común basado en lo que podríamos llamar un humanismo cristiano con fuerte preocupación social.

Las asignaturas de ética, que son obligatorias, procuran sobre todo la formación de la inteligencia del alumno en las cuestiones éticas que afectan al ejercicio de su profesión. Se trata en ellas de hacer un recorrido académico por los dos primeros grandes temas de la ética que mencionamos en el epígrafe 3: reconocer y comprender la dimensión moral del ejercicio profesional, y proporcionar fundamento, método y casos de discernimiento moral de situaciones profesionales típicas. No es raro que se discuta también el estado moral de la profesión y nuestra sociedad en general, lo que corresponde a la tercera área de interés de la ética.

La formación de la afectividad y la volición moral se propone en estas asignaturas de manera más sutil, en parte a través del carisma personal del profesor, en parte a través de las connotaciones del lenguaje, los ejemplos, el enunciado de los ejercicios, etc. En esto, como veremos a continuación, las 'éticas' no se diferencian mucho de otras asignaturas.

\section{La formación moral en las asignaturas específicas de cada carrera}

Una preocupación fundacional del Grupo de Éticas Profesionales de UNIJES ha sido el riesgo de confinamiento de la formación ética a las actividades, académicas - extra-académicas, que la tienen como principal objetivo. Ese riesgo es real en la medida en que la propuesta humanística de UNIJES se sitúa a contracorriente de tres fuerzas culturales con gran influencia sobre nuestros estudiantes: (i) la antropología personal y/o social subyacente a muchas de las teorías vigentes que los alumnos deben estudiar, asimilar y utilizar, como parte de su formación académica; (ii) las prácticas personales y corporativas tenidas por necesarias para el éxito en el mundo profesional (empresa, Estado o tercer sector) al que 
los estudiantes aspiran a incorporarse, o donde ya están insertos; puesto que los profesores quieren que sus estudiantes tengan éxito en su futuro profesional, esas prácticas son frecuentemente comunicadas en clase; (iii) la cultura de consumo y disfrute inmediato de bienes materiales que envuelve a los adultos jóvenes españoles, propuesta desde sus familias, sus pares etarios, y los medios de comunicación social; esa cultura no debe entenderse, por cierto, sólo en términos de atracción hedonística, sino también de miedo al fracaso y la marginación socio-profesional del desempleo o el subempleo.

El riesgo consiste pues en que la formación ética propuesta en nuestras universidades sea contradicha por fuerzas culturales más poderosas presentes dentro de la misma experiencia universitaria de los estudiantes. Esto es, que el discurso ético se convierta en un ornamento piadoso que corona una estructura universitaria ajustada en último término a la ética predominante del éxito. $O$, tomando prestadas las palabras del clásico, que se convierta en "el corazón de un mundo sin corazón, el alma de una situación desalmada" .

En este análisis inicial, la expresión "en la medida en que" (una propuesta de formación moral desde el humanismo cristiano se sitúe contracorriente de estas tendencias) debe ser tomada en serio, puesto que se trata de una medida variable según carreras (puntos i y ii) y grupos socio-culturales de procedencia de los estudiantes (punto iii). Aquí nos ocuparemos únicamente de los dos primeros aspectos, donde estriba la contribución positiva o negativa de las asignaturas específicas de cada carrera a la formación moral de los estudiantes.

\section{I.Antropologías subyacentes}

Para nuestro interés, podemos dividir las ciencias en dos grupos: aquellas que requieren y suponen una antropología, y las que no. En el primer grupo reunimos a las ciencias humanas y sociales, incluyendo parte de las ciencias de la salud. En el segundo grupo situaríamos las ciencias puramente formales y naturales, lo que incluye otra parte de las ciencias de la salud. Como sólo las primeras tienen, en virtud de su misma constitución teórica, una influencia importante en la formación moral de los estudiantes, sólo a ellas vamos a referirnos en este epígrafe.

En las asignaturas de ciencias humanas y sociales se enseñan teorías más o menos vigentes sobre los aspectos de la persona y la sociedad que pertenecen al campo

${ }^{7}$ Karl MARX (1844) Zur Kritik der Hegelschen Rechtsphilosophie. Einleitung. [http://www.mlwerke.de/ $\mathrm{me} / \mathrm{me} 01 / \mathrm{meO1} 378 . \mathrm{htm}]$ 
de la asignatura. Esas teorías pueden ser una sola o varias, dependiendo del grado de consenso o disenso que, en el estado actual del arte, exhiba la correspondiente comunidad científica. A menudo es preciso simplificar en esto, presentando sólo una o dos de las teorías vigentes, o bien presentar varias por relación a una sola 'dominante', sea por preferencia personal del profesor, por necesidades docentes, o por la historia misma del campo.

Cada teoría acota un objeto de estudio, asume unos supuestos más o menos intuitivos relacionados con él, selecciona los fenónemos relevantes, elabora un lenguaje preciso para hablar sobre ellos, diseña un método, y emprende la tarea de explicar y predecir sobre ese ámbito fenoménico, a partir de sus supuestos, empleando su método propio y utilizando los términos teóricos que ha definido. Para tener éxito explicativo, cada teoría necesita reducir la complejidad de lo real hasta niveles manejables. El acierto de esa reducción suele evaluarse por la capacidad predictiva que la teoría exhiba, sea observacional (predecir fenómenos que efectivamente son observados después), o práctica (servir de base para técnicas que hacen ocurrir efectivamente fenómenos considerados deseables).

Hasta aquí nada hay de problemático desde el punto de vista de la ética. No tendría sentido acusar genéricamente a las teorías científicas de reduccionistas, puesto que reducir la complejidad de lo real es una condición constitutiva suya, necesaria para su éxito explicativo y para su utilidad práctica. El problema se nos plantea cuando la reducción incluye la abstracción de la dimensión moral de la existencia humana, haciéndola desaparecer del método, del lenguaje teórico, de los fenómenos considerados relevantes para la ciencia, de sus supuestos, y por tanto de la concepción subyacente del objeto de estudio. Si ello ocurre, la ética desaparece también de las técnicas construidas sobre esas teorías, quedando reducida, si acaso, al rol de constricción externa.

Esa concreta reducción, que ocurre en grados variables en diversas teorías científicas vigentes sobre la persona y la sociedad, es probablemente consecuencia histórica del éxito de las ciencias naturales a partir de Newton. Estableciendo cadenas cerradas de causas y efectos a partir de muy pocos principios, y con un método de observación-experimentación riguroso, muchas ciencias naturales han conseguido grandes éxitos predictivos ${ }^{8}$, que sirven de base a tecnologías confiables de enorme impacto sobre la vida humana. El hecho de que, como Heisenberg

\footnotetext{
${ }^{8}$ No todas, sin embargo. Particularmente problemáticas han resultado las ciencias naturales que se ocupan de sistemas complejos, donde no puede suponerse cierta linealidad entre causas y efectos, como ocurre con la metereología.
} 
notó, cualquier saber sobre el mundo físico esté sometido a un grado irreductible de indeterminación, no empaña la experiencia de control sobre la naturaleza, no sólo creciente sino autoacelerado, que acontece a través de las ciencias naturales modernas como nunca antes en la historia humana?.

No es raro, pues, que a partir del siglo XVIII se intentara reproducir ese éxito en las ciencias humanas y sociales. Empezaron entonces a brotar como hongos los candidatos a 'Newton de las ciencias morales', las propuestas para diversas 'Físicas sociales', y las exhortaciones a callar sobre aquello de lo que no se pueda hablar con referentes estrictamente fenoménicos.

El precio teórico que debió pagarse para perseguir en el universo humano el éxito que Newton había alcanzado en el físico, fue cosificar a las personas, de manera que la incertidumbre que la libre elección introduce en las cadenas causa-efecto fuera eliminada, y pudieran proponerse leyes de estructura semejante a las de las ciencias naturales. En términos de Gabriel Marcel ${ }^{10}$, ello implicaba reducir los misterios a problemas. En términos metodológicos, suponía renunciar a enfoques alternativos como el hermenéutico, donde la libre intencionalidad es reconocida como relevante para comprender todo fenómeno humano-social en cuanto tal. En nuestros términos, significa prescindir de hecho de la dimensión moral de la vida humana.

La forma en que se opera la reducción de la dimensión moral varía de una teoría a otra. En algunos casos, por ejemplo la teoría de la elección racional, se trata de una reducción estadística, que reconoce la existencia de la libertad moral pero supone que las elecciones resultantes de esa libertad pueden predecirse suficientemente bien en los grandes números. En otros casos, como ocurre con muchos estructuralismos, se niega directamente la libertad moral, declarándola un epifenómeno de la operación de estructuras psicosomáticas, sociales, o combinaciones de ambas, que funcionan según cadenas causa-efecto bien determinadas. Hay también teorías, como los diversos evolucionismos sociales, que reducen el papel

\footnotetext{
${ }^{9}$ Esta es la realización del programa enunciado por Francis BACON (1620) Novum Organum, libro I, III: "Scientia et potentia humana in idem coincidunt, quia ignoratio causae destituit effectum. Natura enim non nisi parendo vincitur: et quod in contemplatione instar causae est, id in operatione instar regulae est." ["La ciencia y el poder humano coinciden en que la ignorancia de la causa impide el efecto. A la naturaleza no se la vence pues sino obedeciéndola, y lo que es causa para la contemplación, eso mismo es regla para la operación".] [http://www.thelatinlibrary.com/bacon/bacon.liber 1.shtml]
}

${ }^{10}$ Gabriel MARCEL $(1949 ; 11)$ Position et approches concrètes du mystère ontologique. Lovaina: Nauwelaerts; Paris: J. Vrin. 
de la libertad a la producción de variaciones entre las cuales un mecanismo ciego seleccionará las más aptas para reproducirse y transmitirse.

Infinidad de matices podrían añadirse, pero este recuento incompleto nos bastará para notar la importancia en el panorama actual de las ciencias humano-sociales de aproximaciones teóricas que, de una manera $u$ otra, contradicen la idea de un sujeto libre que, a partir de sus elecciones, crea intencionalmente con otros un mundo donde vivir juntos. Asumir la visión de la persona y la sociedad supuesta en alguno de estos enfoques, lleva a aceptar más o menos conscientemente la inexistencia o la irrelevancia de la dimensión moral de la vida humana. A partir de ahí, el discurso ético queda relegado, bien sea al papel de superestructura más o menos conveniente para el buen funcionamiento del sistema que la teoría describe, bien al de colección de buenas intenciones insignificante, quizás risible, frente a las leyes de hierro del sistema, que la ciencia estudia.

A este desvanecimiento de la ética le acompaña el de la política entendida como indagación de nuevas posibilidades humanizadoras de vida en común, que resulta en la proposición de proyectos de sociedad alcanzables por la acción colectiva. Una política para sociedades cuya dimensión moral ha sido puesta a un lado por las ciencias sociales, pierde el sentido de proyecto común para reducirse a la gestión de preferencias individuales e interacciones estratégicas dentro de 'campos de fuerza' regidos por leyes 'cuasi-naturales', esto es, leyes que replican en la sociedad el vínculo cerrado causa-efecto fundamental en las ciencias de la materia.

El éxito predictivo-técnico de los numerosos programas teóricos que asumen este enfoque en las ciencias humanas y sociales no ha estado a la altura de las expectativas, en un cierto sentido. Tanto las personas como las colectividades han resultado bastante menos predecibles de lo esperado, y las correspondientes operaciones de ingeniería del sujeto, la organización o la sociedad han arrojado a menudo resultados diferentes a los pretendidos. Tal vez por ello, la dimensión moral de la vida humana tiende a retornar en las prácticas profesionales cada vez que se trata de pasar de las teorías a las artes prácticas. No se la ignora sin consecuencias cuando deben obtenerse resultados concretos de las personas, de las organizaciones o de las estructuras sociales. Pero, a menudo, esa reintegración no ocurre en la teoría sino en la consideración prudencial del psicólogo, el comunicador, el mánager, el economista, el abogado o el político, que deben hacerla según su leal saber y entender.

En otro sentido, sin embargo, las teorías de las ciencias humano-sociales que prescinden de la dimensión moral están teniendo éxito: por la peculiar estructura 
de la vida moral, en la medida en que se generalizan, tienden a crear la realidad que describen o suponen. Si la persona entiende que la lógica de funcionamiento de su ámbito de acción profesional hace irrelevante a la dimensión moral de la existencia y a las cuestiones relacionadas con ella, tenderá a interpretar los comportamientos de los demás y actuará él mismo como si así lo fuera, y contribuirá a hacerla, efectivamente, irrelevante. Quienes se relacionen con él obtendrán entonces confirmación de los supuestos de la teoría, y se sentirán inclinados a adoptarla. La vigencia de la teoría se reproducirá a sí misma, cambiando no sólo la visión de la realidad de los actores sino, puesto que los actores actúan con base en su visión de la realidad, también la realidad misma.

Al hacerlo, se notará, teorías que se pretenden en principio descriptivas, operan como si fueran normativas. Dicho con otras palabras, contienen implícitamente una ética, lo que inevitablemente se sigue del hecho de que contienen una antropología, empobrecida o vaciada en cuanto a la dimensión moral, pero no por ello menos antropología.

Una concepción de cómo son la persona y/o la sociedad humana lleva siempre implícita una idea de lo que pueden llegar a ser. Por otra parte, una estructura básica de la existencia moral, reconocida desde antiguo en el derecho ${ }^{11}$, consiste en que el paso del ser al deber-ser viene mediado por el poder-ser. Si la dimensión moral de la existencia estriba en la posibilidad de elegir intencionalmente cómo queremos ser, cómo relacionarnos y qué mundo construir con los demás, teorías que supongan que esa posibilidad no existe o no es relevante para el estudio de los fenómenos humano-sociales, se mueven efectivamente en el terreno de la ética. No utilizar las posibilidades abiertas a la libertad moral, o utilizarlas meramente para aprovechar la comprensión del sistema para alcanzar ciertos objetivos propuestos por el mismo sistema, constituyen ya elecciones morales.

A veces se afirma ${ }^{12}$ que la relación entre la ética y las ciencias humano-sociales es la misma que la que hay entre fines y medios. Las ciencias describirían entonces de manera positiva cómo funciona de hecho la porción del mundo de su interés; mientras que los saberes morales se ocuparían normativamente de lo que debe ser, estableciendo los fines que han de perseguirse. Una vez acordados los fines,

${ }^{11}$ Cessus, en Corpus luris Civilis, Digesta 50.17.185: "Impossibilium nulla obligatio est." [ "No hay obligación ninguna a lo imposible»] [http://upmf-grenoble.fr/Haiti/Cours/Ak/Corpus/d-50.htm\#17]

12 Por ejemplo, respecto a la Economía: Lionel RobBins (1932; 23ss.) An Essay on the Nature and Significance of Economic Science. Londres: McMillan. 
las ciencias entrarían de nuevo en escena para decirnos, dado el funcionamiento del mundo, si pueden alcanzarse esos fines, y cómo. Serían así moralmente neutrales. Este esquema, de nuevo, es tomado del rol social de las ciencias naturales y la tecnología.

Mientras en estas últimas la exterioridad entre medios y fines puede sostenerse razonablemente, puesto que las realidades descritas pueden asimilarse a mecanismos, no ocurre lo mismo en las ciencias humanas y sociales. Por la razón que hemos expuesto ya, lo que la persona humana crea ser ella misma, o su sociedad, repercute inmediatamente sobre lo que le cabe plantearse como posible, y así modifica el horizonte de sus fines. Aparecen bucles desconocidos en las ciencias naturales, como 'lo que puede ser depende, en parte, de lo que el sujeto (persona - colectivo) crea posible'. Si el ser y la operación de la persona y la sociedad se estudian dentro de esquemas lineales causa-efecto o estímulo-respuesta, se ignora que tanto la persona como la sociedad son, en parte, lo que quieran ser, y operan, en parte, como decidan operar. $Y$ como esas decisiones son intencionales, se toman a partir de proyectos de futuro, de manera que el presente no está gobernado únicamente por el pasado sino también por ideas sobre el futuro, por finalidades elegidas.

La descripción de cómo son y cómo operan personas, organizaciones y sociedades no es, pues, lógicamente independiente de las finalidades asumidas por ellas. Hay, por supuesto, límites a la capacidad humana de hacerse a uno mismo y al propio mundo pero, dentro de esos límites, la apertura que la dimensión moral introduce impide que la descripción de lo que será pueda extraerse sin más de la descripción de lo que es.

Por otra parte, 'actuar según la propia naturaleza' constituye un antiguo criterio de moralidad que funciona en muchos casos como premisa mayor implícita de un razonamiento en que la premisa menor viene dada por visiones de la persona y la sociedad tomadas de las ciencias humanas y sociales. Si la persona se describe como naturalmente movida por ciertos impulsos básicos, entonces muchos concluirán que es correcto dejarse llevar por esos impulsos. Si la vida social se describe como un juego cuya naturaleza incluye ciertas reglas, jugar según esas reglas será visto por muchos como correcto. Todo lo cual, según mencionamos arriba, contribuirá efectivamente a transformar a la persona en eso que ella cree 'científicamente' ser y a convertir a la sociedad en el juego descrito por la correspondiente teoría.

¿Cómo puede superarse esta situación teorética en clase, donde sin duda debe explicarse el estado actual de los saberes, y enseñar a los estudiantes las habili- 
dades profesionales que se derivan de ellos? La superación propiamente teórica no puede hacerse en el aula si no se ha hecho antes en la investigación. Ahí es donde deben buscarse caminos para la reintegración de la dimensión moral de la persona y la sociedad en cada una de las ciencias en que haya sido desplazada sin que la entidad de las realidades estudiadas justifique ese desplazamiento. Esto es, cada vez que una ciencia humana o social tenga que habérselas con personas que eligen, o pueden hacerlo, de manera inteligente y libre, la dimensión moral debería formar parte del desarrollo teórico desde su mismo principio. Los problemas éticos aparecerán, entonces, dentro del cuerpo teórico de la ciencia, sin desvanecerse hacia la inexistencia o la irrelevancia, ni externalizarse hacia algún reino extra-académico de los fines, o posponerse hacia 'diálogos interdisciplinares' para los que rara vez hay tiempo, todos tan ocupados en publicar papers según las teorías vigentes. La producción de nueva teoría constituye así una tarea investigativa primordial de la universidad de inspiración humanista, en la medida en que las teorías vigentes en cada ciencia humana o social no alcancen a incorporar la dimensión moral de la existencia.

Pero, claro está, tenemos que dar clase mañana, y en ella hay que enseñar las teorías existentes, no las que querríamos tener pero no tenemos aún. ¿Qué puede hacerse en la docencia, supuesto que nada nuevo nos viene a ayudar desde la investigación? Lo primero, y más obvio, es entregar las teorías vigentes junto con la crítica de sus supuestos. Esa crítica, por lo que aquí nos interesa, debe incluir la descripción de lo que se está dejando afuera, de los aspectos relevantes de la realidad humano-social a los que la teoría sea ciega, incluida la dimensión moral.

Luego, a lo largo del curso, es posible introducir las cuestiones éticas que la teoría en cuestión no puede ver, pero que el punto del desarrollo de la temática permite. Introducir cuestiones éticas consiste, antes que nada, en hacerlas visibles en términos que los estudiantes puedan comprender. Luego, si hay tiempo, se puede facilitar un debate en clase, desde el problema hacia posibles respuestas teóricas y prácticas. Dependiendo de la disposición analítica del profesor, las variadas respuestas que los alumnos presenten pueden ser tratadas orientando la discusión tanto hacia sus fundamentos (qué idea de la persona y la sociedad implican) como hacia sus consecuencias (qué conformación de la persona y la sociedad resultan de ellas, qué técnicas son adecuadas para realizar las mejores opciones éticas). El debate puede perfectamente quedar abierto, dejando el juicio último al estudiante, quien, de todas formas, va a reservárselo. El profesor no necesita dar 'la respuesta correcta', particularmente si la clase se halla ante varias posibilidades razonables. En muchos casos, quizás sea mejor no resolver la perplejidad, sino que baste con crearla. 
La discusión de alguna cuestión ética puede ser incluida en la evaluación; por ejemplo, como parte de un trabajo o incluso en una pregunta de examen. Resulta, sin embargo, esencial, mantener la coherencia metodológica: no se pide al estudiante que sepa y repita una doctrina, sino que demuestre habilidad para plantear y discutir razonadamente un problema ético real del campo de la asignatura.

Evaluar no es en verdad necesario, y sólo debería hacerse si el profesor está seguro de llevarlo a cabo de manera tan adecuada y justa como con los contenidos 'convencionales' de su asignatura. Lo esencial es evitar que la asimilación de teorías deficientes desde el punto de vista antropológico haga de nuestros estudiantes 'creyentes' en ellas, que se forman una visión de la persona y del mundo cerrada a las posibilidades que la dimensión moral nos deja abiertas en nuestro mismo ser individual, relacional y político. Para esto, una visión crítica razonada del profesor, y eventualmente algún debate grupal, serán suficientes.

Una última observación sobre la relación entre las ciencias humano-sociales y la ética. La ciencia moderna es celosa de su autonomía, esto es, de su libertad intelectual para plantear problemas y alcanzar conclusiones utilizando su propio método. Esto debe ser entendido más bien en plural, dado que no hay ciencia sino teorías científicas, y no hay método sino que cada una tiene el suyo. El caso es que el celo por la autonomía deriva en recelo hacia quienquiera que, desde fuera de la respectiva comunidad científica, amague con imponer conclusiones partiendo de principios distintos a los de la misma ciencia. La primera sospechosa, obviamente, es la ortodoxia religiosa: la sombra del caso Galileo es alargada, y se la mantiene intencionalmente viva como paradigma de oposición entre fe y ciencia, sin importar en cuánto anacronismo sea preciso incurrir para ello ${ }^{13}$.

Como se recela de la religión, podría también desconfiarse de la ética. Al fin, tratándose de universidades jesuitas, cabría temer que los modos de interferencia sobre las ciencias que se atribuyen a la ortodoxia religiosa del pasado, sean desarrollados ahora desde una ortodoxia en ética. ¿Affecta este posible temor a nuestra propuesta?

Si se entiende y se practica bien, no. Lo que aquí proponemos no es introducir conclusiones provenientes de la ética en las ciencias humano-sociales, de manera

${ }^{13}$ En realidad, no hace falta religión ninguna para imponer conclusiones, acallar disidentes y limitar el debate científico: como Kuhn mostró, ello se hace frecuentemente desde ortodoxias producidas dentro de las comunidades científicas mismas. El marxismo constituye un ejemplo sobresaliente, pero de ninguna manera el único. Entre nosotros, probablemente haya sido más influyente el positivismo de corte decimonónico. 
que la respuesta a ciertos problemas venga dada antes incluso de empezar la investigación científica. La estructura de nuestra propuesta es justamente la contraria: no se dirige a las conclusiones de la ciencia sino a sus puntos de partida. No pretende introducir respuestas sino evitar que se ignoren preguntas que pertenecen al campo fenoménico estudiado por la ciencia en cuestión, pero que sólo se ponen de manifiesto cuando se considera a la persona humana como sujeto moral y a las sociedades humanas como colectividades morales. Algunas de esas preguntas tienen, por su misma naturaleza, carácter descriptivo; otras tienen carácter normativo. Su conceptualización teórica será distinta, el método preciso para abordarlas y la posibilidad de llegar a acuerdos sobre las respuestas diferirán, pero en todo caso estaremos discutiendo cuestiones relevantes para explicar y predecir fenómenos en el campo de interés de la ciencia. La crítica de los fundamentos antropológicos de las teorías científicas en el campo humano-social, no constituye pues un atentado contra su autonomía sino una invitación a mayor realismo.

\subsection{Los 'otros contenidos'}

Las asignaturas de una carrera contienen a menudo más que instrucción sobre teorías científicas y habilidades que derivan de ellas. Incluyen además otros contenidos con que el profesor trata de poner en relación las teorías con las prácticas profesionales en el campo temático de la asignatura.

La aparición de estos otros contenidos admite grados muy variables de formalidad. En un extremo se encuentran los comentarios informales del profesor sobre 'cómo son las cosas en realidad', las anécdotas que narra de su experiencia profesional, las noticias de actualidad que recoge e interpreta en clase... En el extremo más formal, encontramos las pasantías y prácticas profesionales, o los trabajos de campo que requieren ir 'ahí fuera' y estudiar la realidad en directo. Y, entre ambos, cabe una gama de posibilidades: ejemplos de ilustración de las teorías, casos de estudio, temas de los trabajos, enunciados de los problemas, etc.

Los estudiantes suelen valorar la existencia de estos contenidos, en cuanto les ayudan a encontrar sentido práctico al mundo de los libros en que llevan inmersos casi dos décadas. A sus ojos, esto diferencia a la universidad del bachillerato, y les va poniendo en sintonía con el tiempo anhelado en que habrán salido de la disciplina académica.

Los profesores, por su parte, piensan que al incluir estos contenidos ayudan a preparar a los alumnos para el éxito en el mundo profesional, además de ani- 
mar un poco la clase. Les comunican una experiencia que no se encuentra en las teorías, y que puede ahorrar a los estudiantes errores por ingenuidad que tal vez ellos mismos cometieron al comienzo de sus carreras. La profesión se transmite así a los estudiantes no sólo como un conjunto de teorías y habilidades, sino como introducción a las prácticas y situaciones corrientes del mundo profesional, y al mundo profesional mismo.

El significado moral de esta tarea de introducción es obvio, precisamente porque se trata de comunicar comprensiones del mundo real y modalidades de praxis en él. En esa comunicación se trazan mapas de lo relevante y lo posible en realidad, y se enseña a los estudiantes a orientarse con ellos, contribuyendo a guiar sus elecciones futuras.

Así, el profesor puede concentrarse en los criterios, métodos y ejemplos vigentes de éxito profesional en su campo, o puede abrir el foco e introducir conceptos más amplios de éxito, mostrando formas más complejas de situarse en la realidad, y presentando casos que muestran aspectos del mundo que las teorías o las visiones vigentes tienden a ocultar. Puede revelar, o no hacerlo, contradicciones prácticas que las teorías disfrazan en su búsqueda de coherencia, disyuntivas concretas en que no es posible no optar, porque no eligiendo ya se ha elegido de hecho.

Supongamos un estudiante de management. Su formación para la praxis profesional, que es sin duda parte de su formación moral, no será la misma si ha experimentado algún contacto personal a lo largo de la carrera con el mundo del trabajo manual, que si ha sido acostumbrado a ver la empresa sólo desde el punto de vista directivo. Análogamente, su visión de la tarea directiva no será la misma si la comunicación informal del profesor le ha enseñado a buscar posibilidades no evidentes de conciliación de intereses legítimos, que si sus profesores más influyentes sostenían una aproximación cínica al mundo de los negocios. Y no comprenderá la producción igual si ha visto personalmente un ecosistema devastado por residuos industriales que si sólo sabe de ello por la televisión.

En cada caso, la instrucción teórica puede ser la misma. Sin embargo, la formación moral recibida será muy distinta, en cuanto comprensión del mundo empresarial, de las posibilidades de acción personal en él, y de las posibilidades de transformación social para bien y para mal desde la empresa.

El impacto de estos 'otros contenidos' sobre la formación moral del estudiante depende fundamentalmente de dos factores: cuánto generen de experiencia personal en el alumno, y con cuánta autoridad moral se presenten. Lo primero plantea a 
la universidad jesuita una cuestión formativa de fondo: ¿̨basta la experiencia vital promedio que traen nuestros estudiantes para formar profesionales moralmente responsables?

Como indicamos en el epígrafe 4, la buena voluntad de la persona, que en principio podemos suponer en nuestros estudiantes, no basta. La voluntad opera sobre sensibilidades e intelecciones que forman una visión del mundo más o menos completa y equilibrada. Jóvenes que tienen para gastar en entretenimiento cada mes más dinero que el salario mínimo, sin duda se beneficiarían de entrar en algún contacto personal con la experiencia de los trabajadores no cualificados que luchan por un empleo de 700 euros. Su buena voluntad podrá seguir la misma que antes del contacto, pero la visión del mundo, de lo relevante y lo posible en él, a partir de la cual esa voluntad elegirá, será más compleja y más completa.

Se pensará quizás que este no es asunto de la universidad, menos aún de las asignaturas científicas, sino más bien de ONG, voluntariados, asociaciones juveniles, iglesias y semejantes. Sin embargo, en cuanto respecta a la formación profesional, parece que el ensanchamiento de la experiencia del estudiante sobre el ámbito en que va a actuar directamente como profesional, sí compete a la universidad. Y en cuanto una dimensión o un ámbito de la actividad profesional futura del estudiante sea tematizada en una cierta asignatura, parece que esa asignatura es el lugar adecuado para que el estudiante tenga la oportunidad, voluntaria o mandatoria, de experimentar más allá de su mundo de vida inmediato y de situarse en perspectivas relevantes que no le eran familiares, y que no van a serlo de otra manera.

Junto con la experiencia personal del alumno, también la autoridad moral del profesor influye en el impacto de los 'otros contenidos' de la asignatura. La autoridad moral consiste en una modalidad de liderazgo que dirige a los demás hacia las mejores calidades posibles de las personas, las relaciones interpersonales y las relaciones sociales, o las aparta de ellas. En parte se trata de un fenómeno carismático, en parte resulta de mostrar con el ejemplo que ciertas posibilidades están abiertas y vale la pena seguirlas.

Todos somos sensibles a este tipo de comunicación moral, pero los jóvenes lo son más. El profesor puede encontrarse así con un poder en sus manos que va más allá de su ciencia y de sus habilidades docentes en sentido clásico. Ese poder le transforma en inspirador de sus estudiantes. Y, como ocurre con todo poder, su ejercicio es en sí mismo un asunto moral que el profesor debe sopesar cuidadosamente. 


\section{Excursus: Las asignaturas de ciencias formales y naturales}

Las teorías de las ciencias formales (como la lógica, la matemática y la informática), de las ciencias naturales (química, física, biología...) y de sus derivadas tecnológicas, no están en principio afectadas por la cuestión que planteamos en el epígrafe 6.1, porque no contienen una antropología en su base. La única excepción puede hallarse, dependiendo del enfoque utilizado, en algunas materias de biología humana, por ejemplo la neurofisiología, que podrían incluirse entre las ciencias humanas a estos efectos.

Sin embargo, las carreras científico-tecnológicas constituyen, no menos que las humanístico-sociales, una preparación cercana para incorporarse a praxis profesionales. ¿ Debe el estudiante pasar a través de ellas sin comprender los significados morales de su ejercicio profesional futuro?

Aparte de la asignatura de ética, los lugares académicos para la formación moral en esas carreras son las asignaturas de economía, empresa y semejantes (que están adquiriendo gran relevancia en las ingenierías, por ejemplo) y, siempre, la comunicación de 'otros contenidos' por parte del profesor. Particularmente en las asignaturas de los últimos cursos, donde se estudian los aspectos técnicos más inmediatamente aplicables de la carrera, el profesor puede suscitar y discutir las cuestiones éticas que derivan del uso social de las ciencias formales y naturales, y de las tecnologías derivadas de ellas.

\section{Gobierno universitario y misión de la universidad jesuita}

La reincorporación de la dimensión moral de la persona y la sociedad a la enseñanza universitaria no puede, como hemos querido mostrar, dejarse a unas pocas asignaturas 'identitarias' de la universidad jesuita. Más bien al revés, debe ser considerada una tarea transversal que toca todas las asignaturas, en particular aquellas donde se proponen teorías que suponen concepciones del hombre y de la sociedad, y aquellas donde los profesores comunican visiones del mundo profesional y las prácticas en él.

Para asumir esa tarea en verdad, resulta preciso además enfocar hacia ella no sólo esfuerzos individuales en el aula, sino también: (1) de investigación pura orientados a la reintegración de la dimensión moral en las ciencias humanas y sociales; (2) de investigación aplicada orientados a estudiar formas prácticas de reintegración en 
la vida social, organizacional y profesional; (3) de elaboración pedagógica y de formación del profesorado para que, en cualquier estado de los saberes teóricos que enseñan, sepan cómo abrir a los estudiantes a una comprensión científica de la persona y la sociedad que incluya la dimensión moral.

Ir construyendo esta triple alineación del compromiso de los profesores de las numerosas asignaturas relevantes, de las ideas generadas en la investigación, y del método de enseñanza-aprendizaje, para que la universidad ofrezca una formación moral consistente a sus estudiantes, es tarea última del gobierno de la universidad jesuita. No puede pensarse razonablemente que ocurrirá por una toma de conciencia espontánea en todos los niveles requeridos. Tampoco puede esperarse que resulte de las demandas de los mercados o de los requerimientos de las autoridades educativas. Otros objetivos concentran las presiones que nos vienen de allí.

La universidad jesuita, sin embargo, tiene objetivos propios, aparte de los que recibe de la sociedad. No es una mera satisfactora de demandas o seguidora de lineamientos gubernamentales. Una tradición de cinco siglos de humanismo cristiano avala su compromiso con la integración de la formación moral y la profesional de los estudiantes. Ese compromiso constituye una de sus razones fundamentales de ser, un elemento nuclear de su misión sin el cual perdería sentido el esfuerzo por competir en el mercado de la educación superior, donde, a diferencia de otros tiempos, ahora abunda la oferta de calidad para la adquisición de 'competencias' de valoración inmediata por el mercado ${ }^{14}$.

Si se quiere, se trata de que tenemos nuestra propia idea de calidad de la enseñanza universitaria, una idea que va más allá de ofrecer lo preciso para el éxito del graduado como trabajador o como empresario. Nos interesa también su éxito moral en el ejercicio profesional, y su contribución a proyectos humanizadores de vida en común. Estos objetivos específicos de la educación jesuita requieren una considerable alineación de esfuerzos dentro de la universidad, mucho más allá de unas pocas asignaturas 'identitarias'.

En este propósito suyo, la universidad jesuita no tiene tantos competidores efectivos. El mercado y las autoridades que nos presionan legítimamente en la línea de la competitividad económica, estarían igualmente satisfechos si no existieran las asignaturas 'identitarias' que ya hay. No vendrá de ellos el impulso preciso para

\footnotetext{
${ }^{14}$ Compartimos en esto la discusión más general de ROMERO (2007, tesis 9) sobre la necesidad de 'incrustar' la misión de la universidad jesuita en toda la vida universitaria.
} 
constituir toda la experiencia universitaria de nuestros estudiantes en propuesta de formación moral, resolviendo las limitaciones y contradicciones internas que en este momento podamos experimentar. Ese impulso sólo podrá venir de dentro de la misma universidad, de su gobierno y de todos aquellos docentes y no docentes que se identifican con el proyecto secular de la educación moral jesuita.

\section{Bibliografía}

BLAKE, Nigel \& aLA (eds.) (2003) The Blackwell Guide to the Philosophy of Education. Oxford, UK; Malden, MA: Blackwell Pub.

GeIGER, Roger L. (2004) Knowledge and Money: Research Universities and the Paradox of the Marketplace. Stanford, Calif.: Stanford University Press.

González Fabre, Raúl (2005) Ética y economía. Bilbao: Desclée.

Herrington, Anthony and Herrington, Jan (eds.) (2006) Authentic Learning Environments in Higher Education. Hershey, PA: Information Science Pub.

HoRTAL, Augusto (2002) Ética general de las profesiones. Bilbao: Desclée.

- (2007) "La contribución de las universidades a la dignificación de la vida pública". En Revista de Fomento Social, vol. 62, num. 248, pp. 623-632. Córdoba: octubre-diciembre.

INGLIS, Fred (ed.) (2004) Education and the Good Society. Houndmills, Basingstoke, Hampshire; Nueva York: Palgrave Macmillan.

JenkINS, Alan \& ALIA (2003) Reshaping Teaching in Higher Education: Linking Teaching with Research. Londres; Sterling, VA: Kogan Page.

JuAn Pablo II (1990) Constitución Apostólica Ex Corde Ecclesiae sobrelas Universidades Católicas. [http://www.vatican.va/holy_father/john_paul_ii/apost_constitutions/ documents/hf_ip-ii_apc_15081990_ex-corde-ecclesiae_sp.html]

KolvenBACH, Peter-Hans (2007) Selección de escritos 1991-2007. Madrid: Curia del Provincial de España de la Compañía de Jesús.

Michael, Steve O. and Kretovics, Mark (eds.) (2005) Financing Higher Education in a Global Market. Nueva York: Algora Pub. 
ROMERO, José J. (2007), "Misión de una universidad jesuita: retos y líneas de futuro". En Revista de Fomento Social, vol. 62, num. 247, pp. 393-418. Córdoba: octubre-diciembre.

Staub, Ervin (2003), The Psychology of Good and Evil: Why Children, Adults, and Groups Help and Harm Others. Cambridge, U.K.; Nueva York: Cambridge University Press (ver particularmente pp. 516-550).

ValmaA, Jussi (ed.) (2008), Cultural Perspectives on Higher Education. Nueva York: Springer.

WRINGE, Colin (2006), Moral Education: Beyond the Teaching of Right and Wrong. Dordrecht: Springer.

Zeidler, Dana Lewis (ed.) (2003), The Role of Moral Reasoning on Socioscientific Issues and Discourse in Science Education. Dordrecht; Boston. Kluwer Academic Publishers. 